\title{
The role of mediodorsal thalamic nucleus in fear extinction
}

\author{
Sukchan Lee ${ }^{1}$ and Hee-Sup Shin ${ }^{2^{*}}$
}

\begin{abstract}
Understanding the neural mechanism underlying the formation and extinction of fear memory would guide the development of advanced strategies for treatment of post-traumatic stress disorder (PTSD), a generalized anxiety disorder. The mediodorsal thalamic nucleus (MD) is reciprocally connected with limbic circuitry including the prefrontal cortex and amygdala, key structures for fear formation, and extinction. In addition to the distinctive anatomical relationships, the MD participates in learning and memory process in fear extinction through thalamic dual firing modes: tonic and burst. This review will briefly describe neural mechanisms of fear extinction and highlight the role of $\mathrm{MD}$ in modulation of fear extinction. We suggest that excitability of the MD neurons may modulate fear circuits and can be a novel target for treatment of anxiety disorders.
\end{abstract}

Keywords: Fear extinction, Mediodorsal thalamic nucleus, Dual firing modes (tonic and burst)

\section{Review}

\section{Introduction}

One of the big themes of neuroscience is to understand how the brain systems regulate emotion. Based on learning and memory from threatened conditions, humans continue to adapt to the environment by responding appropriately to a dangerous situation. However, uncontrollable fear may develop an anxiety disorder such as post-traumatic stress disorders (PTSD). As the number of PTSD patients increases for a variety of reasons in the modern society, research activities to understand the mechanism for extinction of traumatic memory have increased exponentially for recent 10 years (Milad and Quirk, 2012).

Fear conditioning and extinction paradigms are used as excellent experimental tools to study the mechanisms of extinction of traumatic memory (LeDoux, 2000; Myers and Davis, 2002). In the fear conditioning, conditioned fear can be memorized by exposure to pairing a neutral conditioned stimulus (CS, tone or light) with a noxious unconditioned stimulus (US, electric footshock). Expression of the previously learned fear (freezing, change of heart rate, and breathing) can be reduced by repeated CS presentations without reinforcement. This process, termed fear extinction,

\footnotetext{
* Correspondence: shin@ibs.re.kr

${ }^{2}$ Center for Cognition and Sociality, Institute for Basic Science, Daejeon

305-338, South Korea

Full list of author information is available at the end of the article
}

is similar to the general therapeutic process used to treat PTSD in human patients. Fear extinction, one of active learning paradigms, has acquisition, consolidation, and retrieval stages. Although extinction learning easily inhibits memory of conditioned fear, extinction memory is fragile, often resulting in fear relapse (Vervliet et al., 2013). To improve the treatment of PTSD, novel pathways to explain neural mechanisms of fear extinction and new methods to reduce fear memory need to be investigated.

\section{Main text \\ Brain structures in fear extinction}

Amygdala Amygdala, a key brain structure in control of fear conditioning and extinction, can be divided largely into four parts: lateral nucleus (LA) and basal nucleus (BA) (together basolateral amygdala complex-BLA), intercalated cell mass (ITC), and central (CE) nucleus (Krettek and Price, 1978; Sah et al., 2003). In the main information flow of fear conditioning, CS is associated with US in the LA. Consolidation of conditioned fear occurs in the BLA. CS information from the thalamus or cortex to the BLA is relayed to several brain areas including the hypothalamus and periaqueductal gray via the $\mathrm{CE}$ for expression of conditioned fear (Pape and Pare, 2010; Pare et al., 2004). 
Accurate roles of the amygdala in acquisition of fear extinction became to be revealed not by amygdala lesions but by pharmacological microinjection into the amygdala. Lesions of the LA and BA changed expression of conditioned fear itself and may have compensation effect (Anglada-Figueroa and Quirk, 2005; Nader et al., 2001; Sotres-Bayon et al., 2004). Infusion of the $\mathrm{N}$-methyl-D-aspartate receptor (NMDAr) antagonist AP5 into the BLA before extinction training impaired extinction recall (Falls et al., 1992), suggesting that fear extinction is new and active learning. In contrast, intra-BLA infusion of NMDAr agonist D-cycloserine facilitated extinction (Sotres-Bayon et al., 2007; Walker et al., 2002). These data show that NMDAr-dependent synaptic plasticity may contribute acquisition and consolidation of fear extinction. Cannabinoid (CB) system in the BLA, also, has a role in fear extinction. CB1 receptor knockout-impaired fear extinction and endogenous cannabinoid levels were increased in the BLA after extinction training (Marsicano et al., 2002).

Amygdala neurons show interesting patterns of unit activity during extinction training. Some LA neurons show response to initial CS trails only, and others show continued response throughout extinction training (Quirk et al., 1995; Repa et al., 2001). After 3 days of complete extinction training, CS-responding neurons in the LA did not show unit activity together with no freezing behaviors of the rats in the extinction training context. However, both of the CS-related unit activity and freezing behaviors were recovered in the different context (Hobin et al., 2003). In the $\mathrm{BL}$, extinction training is correlated with a rapid switch in the balance of CS-evoked activity between two distinct populations of projection neurons. In fear cells (17\% of recorded neurons), subsequent extinction training completely abolished conditioned-induced increase of unit activity, whereas in extinction cells (14\% of recorded neurons), which did not show conditionedinduced activity, the training induced a marked increase of unit activity during extinction training (Herry et al., 2008).

Consolidation of fear extinction occurs in the amygdala. Protein synthesis inhibitor anisomycin blocked extinction (Lin et al., 2003). Several kinase pathways including MAP-kinase and PI3-kinase as well as immediate early genes like c-Fos and EGR-1 are involved in the consolidation of the BLA (Herry and Mons, 2004; Herry et al., 2006; Lin et al., 2003). Brain-derived neurotrophic factor (BDNF) acting through the tyrosine kinase $B$ receptor (TrkB) in the BLA is required for the consolidation of stable extinction memories (Chhatwal et al., 2006). Systemic injection of antidepressant fluoxetine increased synaptic plasticity and BDNF levels in BLA, which may contribute to persistent fear extinction (Karpova et al., 2011).
The amygdala inhibitory circuits have been implicated in the expression of fear extinction (Harris and Westbrook, 1998). Thus, extinction training induced an increased gene and protein expression for the $\mathrm{GABA}(\mathrm{A})$ receptor clustering protein, gephyrin (Chhatwal et al., 2005), an upregulation of gamma-aminobutyric acid (GABA)ergic markers related to enhanced GABAergic transmission (Heldt and Ressler, 2007), and an increased amplitude of GABAergic miniature inhibitory postsynaptic currents (Lin et al., 2009). Fear extinction increased perisomatic parvalbumin and GAD67 around perisomatic inhibitory synapses originating from parvalbumin and cholecystokinin-positive interneurons and silenced fear conditioning-activated neurons in the BL (Trouche et al., 2013). ITC, which receives information about the CS from the BLA, is mainly GABAergic and inhibits output of CE (Ehrlich et al., 2009). ITC lesions caused a marked deficit in the expression of extinction that correlated negatively with the number of surviving ITC neurons (Likhtik et al., 2008). Pre- and postsynaptic changes of GABAergic synapses in the local inhibitory circuits of the BLA and ITC may play a central role in expression of extinction.

Medial prefrontal cortex The medial prefrontal cortex (mPFC) can be divided into four parts: anterior cingulate cortex, prelimbic cortex (PrL), infralimbic cortex (IL), and medial agranular cortex (Berendse and Groenewegen, 1991; Ongur and Price, 2000). Starting from the study of fear extinction impaired by lesions of the ventral mPFC (vmPFC-PrL and IL), a role of the vmPFC in fear extinction has been discovered (Morgan et al., 1993). Lesion of the IL has an effect not on acquisition of extinction but on extinction retrieval, suggesting a role of IL in consolidation (Quirk et al., 2000). Consistently, unit activity of IL neurons was shown not in fear conditioning nor in extinction training but in recall of extinction. Thus, microstimulation of IL during extinction training enhanced extinction recall (Milad and Quirk, 2002). Intra-IL infusion of NMDAr antagonist CPP, sodium channel blocker TTX, or anisomycin did not impair fear conditioning or acquisition of extinction but suppressed recall of extinction (Burgos-Robles et al, 2007; Santini et al., 2004; Sierra-Mercado et al., 2006). Systemic injection of CPP also selectively reduced burst firing in vmPFC neurons (Burgos-Robles et al., 2007). In addition, IL infusion of muscimol $\left(\mathrm{GABA}_{\mathrm{A}}\right.$ receptor agonist) immediately after extinction training blocked recall of extinction (Laurent and Westbrook, 2008). Interestingly, BDNF infused into the IL reduced conditioned fear for up to $48 \mathrm{~h}$, even in the absence of extinction training, and BDNFinduced reduction in fear required $N$-methyl-D-aspartate receptors (Peters et al., 2010).

PrL plays a role in expression of learned fear. Microstimulation of PrL increased the expression of conditioned 
fear and prevented extinction (Vidal-Gonzalez et al., 2006). In addition, unit activity of the PrL was positively correlated with expression of conditioned fear and extinction failure (Burgos-Robles et al., 2009). Consistent with a role of the PrL, virally mediated prelimbic cortical-specific gene deletion of BDNF had no effect on fear extinction (Choi et al., 2010).

It is thought that IL neurons inhibit expression of conditioned fear by activating the ITC of the amygdala in recall of extinction and PrL neurons induce expression of conditioned fear by activating the BA (Cho et al., 2013; Sotres-Bayon and Quirk, 2010). More studies for interaction between the vmPFC and amygdala in fear conditioning and extinction are needed.

\section{Mediodorsal thalamic nucleus in fear extinction}

The mediodorsal thalamic nucleus (MD) is one of nonspecific nuclei of the thalamus. The PFC can be defined as the projection area of the MD, which is connected with the amygdala forming a tight triangular circuitry (Fig. 1) (Jones, 2007; Kuroda et al., 1998; Ray and Price, 1992). Consistent with the anatomical connection of the MD, a lesion of the MD leads to impairment of function associated with PFC or amygdala: working memory, association memory, emotion, attention, and learning (Hunt and Aggleton, 1998; Mitchell and Dalrymple-Alford, 2005; Mitchell and Gaffan, 2008; Van der Werf et al., 2000; Zoppelt et al., 2003). Anatomical and lesion studies suggest that activation of the MD, as a key player in the attention/intention circuits, may be required for encoding new information into memory because attention is required to suppress any unwanted thought and feelings (Ray and Price, 1992, 1993; Smythies, 1997). Therefore, the MD may have a role as a cognitive hub in the basolateral limbic circuits (the amygdala, mPFC, and MD) of the learning and memory processes.

The first data implicating the MD in fear extinction came from study for plasticity in thalamo-prefrontal cortical transition in consolidation of fear extinction (Herry and Garcia, 2002; Herry et al., 1999). Low-frequency stimulation (LFS) and high-frequency stimulation (HFS) of the MD induced prefrontal long-term depression (LTD) and potentiation (LTP), respectively. The LTD induced prior to extinction learning suppressed fear extinction, whereas the LTP induced prior to extinction learning enhanced recall of extinction (Herry and Garcia, 2002; Hugues and Garcia, 2007). HFS of the MD also induced a consistent LTP in the amygdala (Zhang and Bertram, 2002). It might be expected that the MD is also a site of acquisition and consolidation of extinction, interacting with the amygdala and mPFC.

An experiment combining genetics, pharmacology, physiology, and microstimulation revealed a role for the $\mathrm{MD}$ in extinction learning, especially suggesting that the firing mode of the MD is critical in modulation of fear extinction (Lee et al., 2012). Thalamocortical neurons exhibit two distinct firing modes depending on membrane status: a low voltage-activated T-type $\mathrm{Ca}^{2+}$ channel-dependent burst of high-frequency action potentials upon hyperpolarization or tonic firing of singular action potentials during depolarization (Llinas and Jahnsen, 1982; Sherman, 2001). Here, activation of metabotropic glutamate receptor type 1 (mGluR1) induces membrane depolarization in thalamocortical neurons, leading to a shift in thalamic firing from the burst to the tonic mode (McCormick and von Krosigk, 1992). The mice with a knockout of phospholipase C- $\beta 4$

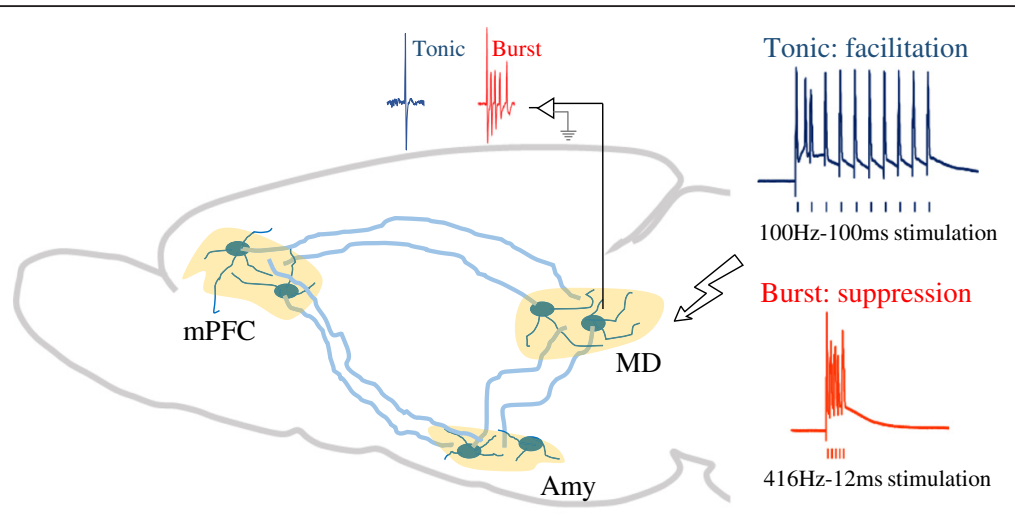

Fig. 1 The bidirectional modulation of fear extinction by thalamic dual firing (tonic and burst) in MD. The mediodorsal thalamic nucleus (MD), a part of the basolateral limbic system, has strong interconnections with the medial prefrontal cortex (mPFC) as well as with the amygdala (Amy), and these regions together form a tight triangular circuitry. Tetrode recordings in freely moving mice revealed that the increased frequency of tonic firing of MD neurons is positively correlated with the development of fear extinction and that frequency of T-type Ca ${ }^{2+}$-dependent burst spikes was increased in the PLC $\beta 4^{-1-}$ mice, which showed impaired fear extinction. Moreover, electrical microstimulation with a protocol increasing tonic firing in the MD facilitates fear extinction in both of wild type and PLC $\beta 4^{-/-}$mice. These results suggest that an increase of tonic firing in the MD is necessary for fear extinction. In contrast to the role of tonic firing, electrical microstimulation with a protocol mimicking burst spikes in the MD suppresses fear extinction (Lee et al., 2012) 
(PLC 34$)$, which is physiologically coupled with mGluR1, were strongly impaired in acquisition of extinction. MDspecific knockdown of PLC $\beta 4$ leads to similar impairment in extinction. Intra-MD infusion of CPCCOEt, a selective mGluR1 antagonist, or mibefradil, a general T-type $\mathrm{Ca}^{2+}$ channel inhibitor, before extinction training inhibited acquisition of extinction. Interestingly, the degree of the increase of tonic firing of the MD during the acquisition stage of extinction was positively correlated with the strength of recall of extinction. On the other hand, burst firing of the MD in PLC $\beta 4$-deficient mice was enhanced. Consistent with unit activity of the MD, tonic-evoked microstimulation of the MD, paired with CS, facilitated extinction learning. In contrast, burst-evoked microstimulation of the MD, paired with CS, suppressed extinction learning (Fig. 1). Thus, the MD could be involved in acquisition and consolidation of fear extinction within the triangular circuit including the mPFC and amygdala.

\section{Conclusions}

Although the mechanism how the MD interacts with the amygdala or mPFC in fear extinction remains to be further investigated, the novel strategy controlling the excitability (burst and tonic firing modes) of the MD might help in the treatment of anxiety disorders. In the future, these studies for fear extinction may make the traumatic past of the patients left behind, helping the patients live in the present.

\section{Competing interests}

The authors declare that they have no competing interests.

\section{Authors' contributions}

$\mathrm{SL}$ and $\mathrm{H}$-SS wrote the manuscript. Both authors read and approved the final manuscript.

\section{Acknowledgements}

This work was supported by grants from the Institute for Basic Science (IBS-R001-D1).

\section{Author details}

'Department of Physiology, Seoul National University College of Medicine, Seoul 110-799, South Korea. ${ }^{2}$ Center for Cognition and Sociality, Institute for Basic Science, Daejeon 305-338, South Korea.

Received: 10 April 2016 Accepted: 3 May 2016

Published online: 13 May 2016

\section{References}

Anglada-Figueroa D, Quirk GJ. Lesions of the basal amygdala block expression of conditioned fear but not extinction. J Neurosci Off J Soc Neurosci. 2005;25:9680-5. Berendse HW, Groenewegen HJ. Restricted cortical termination fields of the midline and intralaminar thalamic nuclei in the rat. Neuroscience. 1991;42:73-102.

Burgos-Robles A, Vidal-Gonzalez I, Quirk GJ. Sustained conditioned responses in prelimbic prefrontal neurons are correlated with fear expression and extinction failure. J Neurosci Off J Soc Neurosci. 2009;29:8474-82.

Burgos-Robles A, Vidal-Gonzalez I, Santini E, Quirk GJ. Consolidation of fear extinction requires NMDA receptor-dependent bursting in the ventromedial prefrontal cortex. Neuron. 2007;53:871-80.

Chhatwal JP, Myers KM, Ressler KJ, Davis M. Regulation of gephyrin and GABAA receptor binding within the amygdala after fear acquisition and extinction. J Neurosci Off J Soc Neurosci. 2005;25:502-6.
Chhatwal JP, Stanek-Rattiner L, Davis M, Ressler KJ. Amygdala BDNF signaling is required for consolidation but not encoding of extinction. Nat Neurosci. 2006; $9: 870-2$.

Cho JH, Deisseroth K, Bolshakov VY. Synaptic encoding of fear extinction in mPFC-amygdala circuits. Neuron. 2013;80:1491-507.

Choi DC, Maguschak KA, Ye K, Jang SW, Myers KM, Ressler KJ. Prelimbic cortical BDNF is required for memory of learned fear but not extinction or innate fear. Proc Natl Acad Sci U S A. 2010;107:2675-80.

Ehrlich I, Humeau Y, Grenier F, Ciocchi S, Herry C, Luthi A. Amygdala inhibitory circuits and the control of fear memory. Neuron. 2009;62:757-71.

Falls WA, Miserendino MJ, Davis M. Extinction of fear-potentiated startle: blockade by infusion of an NMDA antagonist into the amygdala. J Neurosci Off J Soc Neurosci. 1992;12:854-63.

Harris JA, Westbrook RF. Evidence that GABA transmission mediates context-specific extinction of learned fear. Psychopharmacology (Berl). 1998;140:105-15.

Heldt SA, Ressler KJ. Training-induced changes in the expression of GABAAassociated genes in the amygdala after the acquisition and extinction of Pavlovian fear. Eur J Neurosci. 2007;26:3631-44.

Herry C, Ciocchi S, Senn V, Demmou L, Muller C, Luthi A. Switching on and off fear by distinct neuronal circuits. Nature. 2008;454:600-6.

Herry C, Garcia R. Prefrontal cortex long-term potentiation, but not long-term depression, is associated with the maintenance of extinction of learned fear in mice. J Neurosci Off J Soc Neurosci. 2002;22:577-83.

Herry C, Mons N. Resistance to extinction is associated with impaired immediate early gene induction in medial prefrontal cortex and amygdala. Eur J Neurosci. 2004;20:781-90

Herry C, Trifilieff P, Micheau J, Luthi A, Mons N. Extinction of auditory fear conditioning requires MAPK/ERK activation in the basolateral amygdala. Eur J Neurosci. 2006; 24:261-9.

Herry C, Vouimba RM, Garcia R. Plasticity in the mediodorsal thalamo-prefrontal cortical transmission in behaving mice. J Neurophysiol. 1999;82:2827-32.

Hobin JA, Goosens KA, Maren S. Context-dependent neuronal activity in the lateral amygdala represents fear memories after extinction. J Neurosci Off J Soc Neurosci. 2003;23:8410-6.

Hugues S, Garcia R. Reorganization of learning-associated prefrontal synaptic plasticity between the recall of recent and remote fear extinction memory. Learn Mem. 2007;14:520-4.

Hunt PR, Aggleton JP. Neurotoxic lesions of the dorsomedial thalamus impair the acquisition but not the performance of delayed matching to place by rats: a deficit in shifting response rules. J Neurosci Off J Soc Neurosci. 1998;18: $10045-52$.

Jones EG. The thalamus, 2nd ed. edn. Cambridge: Cambridge University Press; 2007.

Karpova NN, Pickenhagen A, Lindholm J, Tiraboschi E, Kulesskaya N, Agustsdottir A, Antila H, Popova D, Akamine Y, Bahi A, et al. Fear erasure in mice requires synergy between antidepressant drugs and extinction training. Science. 2011;334:1731-4.

Krettek JE, Price JL. A description of the amygdaloid complex in the rat and cat with observations on intra-amygdaloid axonal connections. J Comp Neurol. 1978; 178:255-80

Kuroda M, Yokofujita J, Murakami K. An ultrastructural study of the neural circuit between the prefrontal cortex and the mediodorsal nucleus of the thalamus. Prog Neurobiol. 1998:54:417-58.

Laurent V, Westbrook RF. Distinct contributions of the basolateral amygdala and the medial prefrontal cortex to learning and relearning extinction of context conditioned fear. Learn Mem. 2008;15:657-66.

LeDoux JE. Emotion circuits in the brain. Annu Rev Neurosci. 2000;23:155-84.

Lee S, Ahmed T, Lee S, Kim H, Choi S, Kim DS, Kim SJ, Cho J, Shin HS. Bidirectional modulation of fear extinction by mediodorsal thalamic firing in mice. Nat Neurosci. 2012;15:308-14.

Likhtik E, Popa D, Apergis-Schoute J, Fidacaro GA, Pare D. Amygdala intercalated neurons are required for expression of fear extinction. Nature. 2008;454:642-5.

Lin CH, Yeh SH, Lu HY, Gean PW. The similarities and diversities of signal pathways leading to consolidation of conditioning and consolidation of extinction of fear memory. J Neurosci Off J Soc Neurosci. 2003;23:8310-7.

Lin HC, Mao SC, Gean PW. Block of gamma-aminobutyric acid-A receptor insertion in the amygdala impairs extinction of conditioned fear. Biol Psychiatry. 2009;66:665-73.

Llinas $\mathrm{R}$, Jahnsen $\mathrm{H}$. Electrophysiology of mammalian thalamic neurones in vitro. Nature. 1982;297:406-8.

Marsicano G, Wotjak CT, Azad SC, Bisogno T, Rammes G, Cascio MG, Hermann H, Tang J, Hofmann C, Zieglgansberger, W, et al. The endogenous cannabinoid system controls extinction of aversive memories. Nature. 2002;418:530-4. 
McCormick DA, von Krosigk M. Corticothalamic activation modulates thalamic firing through glutamate "metabotropic" receptors. Proc Natl Acad Sci U S A. 1992;89:2774-8

Milad MR, Quirk GJ. Neurons in medial prefrontal cortex signal memory for fear extinction. Nature. 2002;420:70-4.

Milad MR, Quirk GJ. Fear extinction as a model for translational neuroscience: ten years of progress. Annu Rev Psychol. 2012;63:129-51.

Mitchell AS, Dalrymple-Alford JC. Dissociable memory effects after medial thalamus lesions in the rat. Eur J Neurosci. 2005;22:973-85.

Mitchell AS, Gaffan D. The magnocellular mediodorsal thalamus is necessary for memory acquisition, but not retrieval. J Neurosci Off J Soc Neurosci. 2008;28: 258-63.

Morgan MA, Romanski LM, LeDoux JE. Extinction of emotional learning: contribution of medial prefrontal cortex. Neurosci Lett. 1993;163:109-13.

Myers KM, Davis M. Behavioral and neural analysis of extinction. Neuron. 2002;36: 567-84.

Nader K, Majidishad P, Amorapanth P, LeDoux JE. Damage to the lateral and central, but not other, amygdaloid nuclei prevents the acquisition of auditory fear conditioning. Learn Mem. 2001;8:156-63.

Ongur D, Price $J$. The organization of networks within the orbital and medial prefrontal cortex of rats, monkeys and humans. Cereb Cortex. 2000;10:206-19.

Pape HC, Pare D. Plastic synaptic networks of the amygdala for the acquisition, expression, and extinction of conditioned fear. Physiol Rev. 2010:90:419-63.

Pare D, Quirk GJ, Ledoux JE. New vistas on amygdala networks in conditioned fear. J Neurophysiol. 2004;92:1-9.

Peters J, Dieppa-Perea LM, Melendez LM, Quirk GJ. Induction of fear extinction with hippocampal-infralimbic BDNF. Science. 2010;328:1288-90.

Quirk GJ, Repa C, LeDoux JE. Fear conditioning enhances short-latency auditory responses of lateral amygdala neurons: parallel recordings in the freely behaving rat. Neuron. 1995;15:1029-39.

Quirk GJ, Russo GK, Barron JL, Lebron K. The role of ventromedial prefrontal cortex in the recovery of extinguished fear. J Neurosci Off J Soc Neurosci. 2000;20:6225-31.

Ray JP, Price JL. The organization of the thalamocortical connections of the mediodorsal thalamic nucleus in the rat, related to the ventral forebrainprefrontal cortex topography. J Comp Neurol. 1992;323:167-97.

Ray JP, Price JL. The organization of projections from the mediodorsal nucleus of the thalamus to orbital and medial prefrontal cortex in macaque monkeys. J Comp Neurol. 1993;337:1-31.

Repa JC, Muller J, Apergis J, Desrochers TM, Zhou Y, LeDoux JE. Two different lateral amygdala cell populations contribute to the initiation and storage of memory. Nat Neurosci. 2001;4:724-31.

Sah P, Faber ES, Lopez De Armentia M, Power J. The amygdaloid complex: anatomy and physiology. Physiol Rev. 2003;83:803-34.

Santini E, Ge H, Ren K, Pena de Ortiz S, Quirk GJ. Consolidation of fear extinction requires protein synthesis in the medial prefrontal cortex. J Neurosci Off J Soc Neurosci. 2004;24:5704-10.

Sherman SM. Tonic and burst firing: dual modes of thalamocortical relay. Trends Neurosci. 2001:24:122-6.

Sierra-Mercado Jr D, Corcoran KA, Lebron-Milad K, Quirk GJ. Inactivation of the ventromedial prefrontal cortex reduces expression of conditioned fear and impairs subsequent recall of extinction. Eur J Neurosci. 2006;24:1751-8.

Smythies J. The functional neuroanatomy of awareness: with a focus on the role of various anatomical systems in the control of intermodal attention. Conscious Cogn. 1997;6:455-81.

Sotres-Bayon F, Bush DE, LeDoux JE. Emotional perseveration: an update on prefrontal-amygdala interactions in fear extinction. Learn Mem. 2004;11:525-35.

Sotres-Bayon F, Bush DE, LeDoux JE. Acquisition of fear extinction requires activation of NR2B-containing NMDA receptors in the lateral amygdala. Neuropsychopharmacology. 2007;32:1929-40.

Sotres-Bayon F, Quirk GJ. Prefrontal control of fear: more than just extinction. Curr Opin Neurobiol. 2010;20:231-5.

Trouche S, Sasaki JM, Tu T, Reijmers LG. Fear extinction causes target-specific remodeling of perisomatic inhibitory synapses. Neuron. 2013;80:1054-65.

Van der Werf YD, Witter MP, Uylings HB, Jolles J. Neuropsychology of infarctions in the thalamus: a review. Neuropsychologia. 2000;38:613-27.

Vervliet B, Craske MG, Hermans D. Fear extinction and relapse: state of the art. Annu Rev Clin Psychol. 2013:9:215-48.

Vidal-Gonzalez I, Vidal-Gonzalez B, Rauch SL, Quirk GJ. Microstimulation reveals opposing influences of prelimbic and infralimbic cortex on the expression of conditioned fear. Learn Mem. 2006;13:728-33.
Walker DL, Ressler KJ, Lu KT, Davis M. Facilitation of conditioned fear extinction by systemic administration or intra-amygdala infusions of D-cycloserine as assessed with fear-potentiated startle in rats. J Neurosci Off J Soc Neurosci. 2002;22:2343-51.

Zhang DX, Bertram EH. Midline thalamic region: widespread excitatory input to the entorhinal cortex and amygdala. J Neurosci Off J Soc Neurosci. 2002;22: 3277-84.

Zoppelt D, Koch B, Schwarz M, Daum I. Involvement of the mediodorsal thalamic nucleus in mediating recollection and familiarity. Neuropsychologia. 2003;41: 1160-70.

\section{Submit your manuscript to a SpringerOpen ${ }^{\circ}$ journal and benefit from:}

- Convenient online submission

- Rigorous peer review

- Immediate publication on acceptance

- Open access: articles freely available online

- High visibility within the field

- Retaining the copyright to your article

Submit your next manuscript at $>$ springeropen.com 